
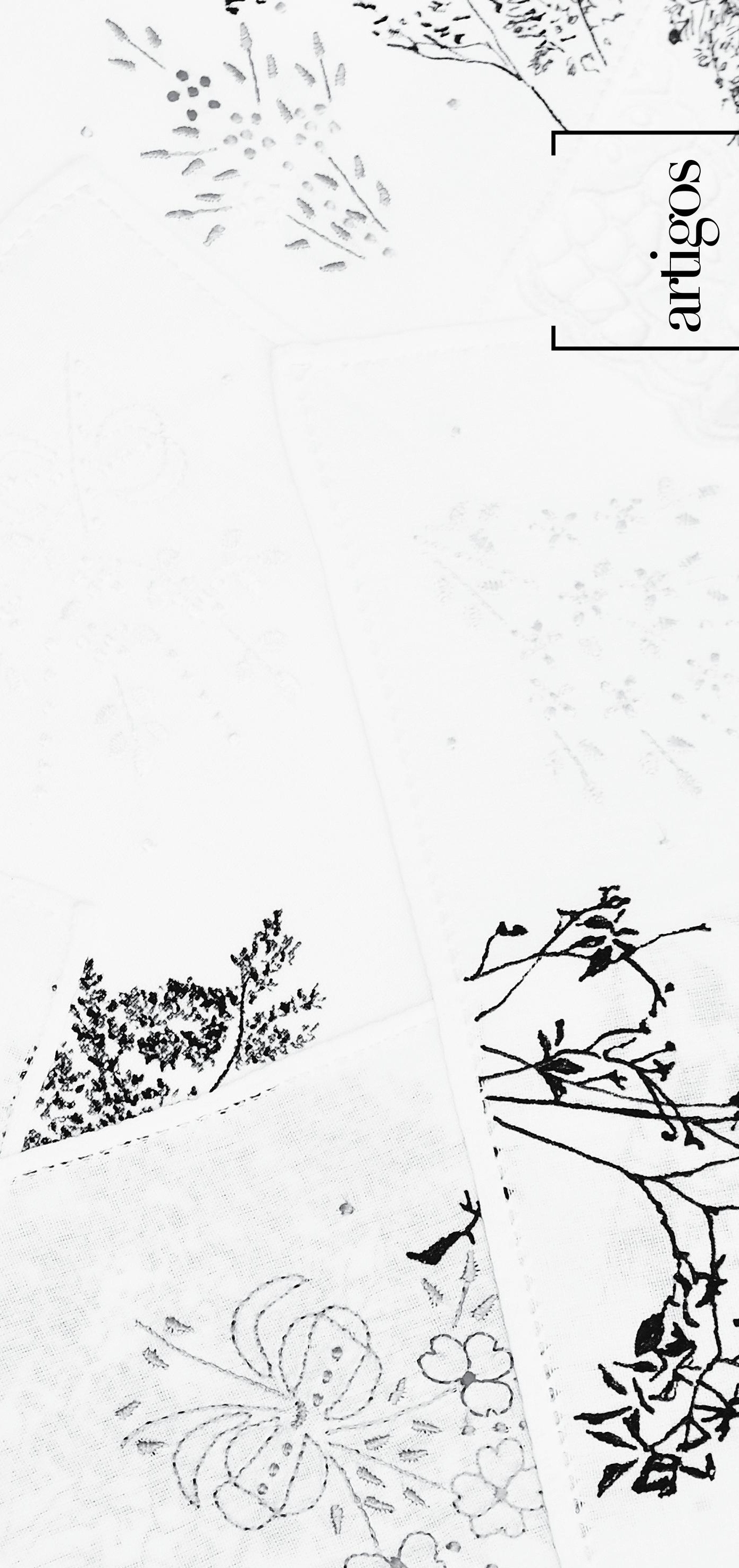
artigo $]_{\text {[ PIERLUIGI CERVELLI ] }}$

Doutor em Semiótica e Psicologia da Comunicação simbólica pela Universidade de Siena. Desenvolve trabalhos de etnosemiótica aplicada ao consumo para algumas empresas e na periferia de Roma concentrando-se em temas como habitação e a marginalidade da imigração.

Leciona no campo da gestão de recursos humanos, planejamento e organização do trabalho, dinâmica de grupo e leadership e na comunicação Desde 2009 é pesquisador junto ao Departamento de Comunicação e Pesquisa Social na Faculdade de Ciência Politica, Sociologia e Comunicação da Universidade de Roma. Sua área de especialização de pesquisas é o estudo da semiótica do espaço em relação à marginalização urbana em particular à marginalização urbana, periferia, imigração e globalização.

E-mail: pierluigi.cervelli@uniroma1.it

\title{
A capacidade comunicativa do objeto anônimo'
}

\author{
The communicative ability of the \\ anomymous object
}

[resumo] 0 objetivo deste artigo é refletir sobre os objetos de design anônimo sob a perspectiva analítica da semiótica. Partindo das contribuições desenvolvidas na Itália sobre o design anônimo e sobre a história do design, especialmente por Eco (1982) e Bassi (2007), recupera a hipótese, sugerida por Eco, de que os objetos de design anônimo comunicam de forma sintética e eficaz não apenas o que fazem, mas como devem ser usados. Sustenta-se que é precisamente essa característica que distingue os objetos anônimos das produções em massa. Por fim, por meio de uma comparação entre dois objetos à primeira vista idênticos, um anônimo e uma cópia de baixa qualidade, procura-se mostrar a relação entre a configuração do objeto - as relações entre as partes que o compõem - e as comunicações de uso.

\section{[palavras-chave}

design anônimo; objeto anônimo; semiótica; comunicação.

[abstract] This article deals with anonymous design from a semiotic point of view. On the basis of history of design (BASSI, 2007) and semiotics (ECO, 1982) reflections developed in Italy, we argue that configuration of anonymous design objects shows a particular form of communication. As Eco suggested, they are able to communicate not only what they do but how to use them. Our hypothesis is that this specific communicative power may be useful for distinguishing mass and low quality productions from design anonymous objects, being one of its main features. By finally analyzing two objects, one recognizable as anonymous design and it's low quality copy, we try to consider in which way the communication of the use is related to the configuration of the object.

[keywords] anonymous design; anonymous object; semiotics; communication. 
0 objetivo deste artigo é tecer algumas reflexões sobre os objetos de design anônimo: definição que se aplica geralmente aos objetos comuns de uso cotidiano, cuja interação conosco é tão importante quanto discreta: garfos e facas, garrafas de vinho, saca-rolhas e fitas métricas, martelos e pregos, calçadeiras e pratos. São objetos geniais sem gênios, fruto de uma longa bricolagem sem um autor que os tenha levado a assumir as formas atuais, aprimoradas pelo tempo e pelo uso, e que nos permitem transformar o cumprimento das necessidades diárias em uma atividade fluida, de modo transparente, adaptando-se a nós e às nossas necessidades.

Depois de utilizados, podem ser facilmente guardados, e este é outro traço que os caracteriza e constitui uma dimensão de sua eficácia: além dos pontos de tomada, há os pontos de conexão ou de inserção, que facilitam a sua relação com os espaços domésticos. Na era do design de luxo, muitas vezes incômodo, o seu encanto é uma questão de síntese.

\section{O design anônimo e vida cotidiana}

0 tema do design anônimo não é novo, mas não há muitas contribuições de reflexão sobre a questão. Algumas, particularmente interessantes para nossa discussão, entrelaçam semioticistas e designers. Refiro-me, em particular, ao livro Design anonimo in Italia, trabalho de Alberto Bassi (2007), que apresenta uma lista longa e acurada de objetos de uso comum, cujos autores são desconhecidos, ou simplesmente ninguém se lembra deles, uma vez que sua concepção é atribuída a grupos, a estúdios de design comercial, polos industriais e não a uma única pessoa.

Qual é o ponto de origem - segundo o autor - da própria ideia de design anônimo? Para Bassi (2007), vem - em grande parte - da semiótica e, em particular, de uma observação de Eco (1982), que chamou a atenção para o fato de que, quando pensamos em design, não podemos deixar de lado os objetos geniais e de uso comum que são design antes do design industrial.

Eco (1982, p. 128) afirma:

Falamos de design, mas não só de design industrial: as reflexões realizadas entre a segunda metade do século passado e a primeira metade deste século, sobre a idéia de design no mundo industrial, levaram a reconhecer que existia o design mesmo antes da era industrial, mesmo antes dos teares mecânicos do século XVIII. A mulher do Neolítico (...) que pela primeira vez molhou argila e a fez girar sobre uma roda, criando a forma do vaso (perfeita, funcional, revolucionária) fez design.

0 autor cita ainda a garrafa de vinho, as ferramentas do agricultor e do ferreiro, as máquinas de café, as tesouras, declarando que falar de design italiano significa, em primeiro lugar, falar desses objetos, sem os quais não se entende nem o que é a Itália (como os italianos vivem através desses objetos), nem o que é o design (como produção de objetos úteis e bonitos). A fim de colocar esses objetos de uso comum entre outros produtos comumente chamados "de design", mas em um panorama mais amplo e diversificado, Eco (1982, p. 128) propõe uma tipologia articulada em três tipos:

- 0 design assinado, efeito de uma teoria expressa e de uma prática em que o objeto pretende demonstrar claramente a teoria de seu autor; pertencem a esta categoria o Edifício Seagram, o carro desenhado por Pininfarina, além do submarino ou a máquina de guerra projetada por Leonardo da Vinci.

- 0 design não assinado (de cuja assinatura ninguém se lembra, ainda que houvesse um único autor); este design não tem nenhuma teoria explícita ou, se tiver, não pretende demonstrá-la; o autor, conhecido ou anônimo que seja, queria apenas resolver um problema prático.

- 0 design inconsciente; uso este termo porque não me parece adequado falar, como se faz, de design "selvagem"; enquadram-se nesta categoria as ferramentas do agricultor ou do ferreiro (...); quem construía esses objetos não pensava em ser um designer, nem em demonstrar uma teoria; (...) preocupava-se apenas em produzir um objeto capaz de funcionar (...). 
A classificação de três critérios propostos por Bassi (2007) parte da divisão de Eco (1982): o design anônimo determina-se a partir de objetos cujo autor foi esquecido, objetos cujo autor nunca foi destacado, atribuindo-os a estúdios de design comercial e a objetos de direitos autorais, mas de larguíssima difusão e custo baixíssimo. É certamente útil e adequada do ponto de vista de uma análise histórico-crítica, mas não nos explica a eficácia funcional estética e sobretudo comunicativa dos objetos de design anônimo, destacada por Eco (1982, p. 129), quando afirma que "As tesouras são uma obra-prima de design: não apenas cortam, mas dizem como devem ser manuseadas". Isso, em particular, não parece completamente solucionável em termos de design ou de autoria, e não parece ser determinado por uma taxonomia. Portanto, é necessário aprofundar a capacidade dos objetos - como a tesoura citada por Eco (1982) - que "dizem como ser usados", contendo em sua própria configuração as instruções para 0 uso, ou melhor, são capazes de comunicar uma sintaxe de ação, e dessa forma o modo como devem ser inseridos em uma prática.

Por meio de alguns exemplos diferentes entre si, mas relacionados com a vida cotidiana (a configuração e o uso do bar, os compartimentos ferroviários, os garfos de sobremesa), Eco (1982) propôs a ideia - interessante porque rejeita uma hierarquização a priori - de que os objetos de design anônimo e os assinados não fazem parte de histórias diversas ${ }^{2}$, uma vez que também os objetos assinados respondem a uma necessidade, a um modo de vida.

\section{A eficácia comunicativa dos objetos anônimos}

Bassi $(2007$, p. 12) considera de indispensável atualidade a reflexão de Eco, quando este autor afirma que: "Muitos dos projetos de design assinado produziram, além da crise e da decepção com a derrota da utopia, uma cultura do design anônimo. Essa cultura do design anônimo é contraditória, abriga objetos kitsch, inúteis, inadequados para a sua função, mas também objetos humildes e bonitos e ao mesmo tempo eficazes, que fazem o que devem fazer e dizem a todos como devem ser usados, e do ponto de vista simbólico contam como o italiano médio vive, trabalha e se diverte" (ECO, 1982, p. 132).

Do mesmo modo, Bassi (2007) ressalta que nem todo design anônimo tem, de fato, as características dos objetos citados por Eco (1982), fazendo parte de uma depreciação geral no panorama dos objetos que nos cercam. Outros autores, como Paris (2005), ressaltaram, no mesmo sentido, como o objeto anônimo às vezes contribui para a poluição da vida cotidiana, entendendo por objetos anônimos falsificações, mau uso, banalizações medíocres.

Ambas as argumentações parecem-me inquestionáveis: certos objetos de design assinados parecem completamente opostos àqueles que Bassi (2007) propõe como exemplos de sucesso de design anônimo, e é inegável que muitos objetos banalizados provoquem uma poluição da vida cotidiana. Refletindo sobre a eficácia comunicativa dos objetos, seja talvez possivel fazer alguma distinção.

Desse ponto de vista, também pode surgir a diferença entre uma abordagem semiótica e uma abordagem histórico-técnica sobre o design: as pesquisas semióticas estão interessadas no modo pelo qual os objetos de design constroem um ponto de vista para o usuário e inscrevem um projeto de uso - um conjunto de instruções para a utilização e de possiveis conexões entre o objeto e o usuário - na configuração interna do próprio objeto.

0 caso do design anônimo é particularmente importante, porque o uso (e o projeto de uso) inscrito nos objetos os define completamente, uma vez que são geralmente desprovidos de caracteristicas paratextuais (a começar por um nome próprio e pelo nome do inventor) sempre presentes nos objetos autorais. Nos objetos anônimos, 0 uso é tudo o que permanece.

Bassi (2007, p. 14) lembra que:

0 anonymous se coloca em um território de fronteira que é difícil de circunscrever de modo unívoco e pontual. Em primeiro lugar, em relação ao próprio status: é essencialmente um objeto-utensílio: faz o que deve fazer, responde estritamente à função para a qual foi concebido. Não é atribuivel a uma única modalidade projetual; em alguns casos, [trata-se de] uma espécie de projeto coletivo.

Por esse motivo, Eco (1982) pode interrogar-se sobre a questão da identidade dos objetos anônimos, enfatizando a função de objetos culturais e comunicativos: uma 
espécie de imagem refletida em pequena escala na qual se pode ler o estilo de vida da comunidade em que são estabelecidos. 0 exemplo dado por Eco (1982) sobre a diferença entre os bares italianos e os estadunidenses considera tanto o design interno (o bar italiano prevê um consumo em pé no balcão e dispõe de poucas cadeiras) quanto as próprias dimensões do café produzido pelas máquinas de café, que são objetos anônimos. 0 design, portanto, está relacionado com um certo estilo de consumo ligado à articulação da hora do dia e aos modos de interação com os outros usuários.

Na reflexão de Eco (1982), a eficácia comunicativa e funcional do design anônimo se liga à sua essencialidade: o design anônimo é aquele que reduz ao mínimo seus elementos constitutivos, prescindindo completamente da decoração (que caracteriza muitos objetos de design assinado). Esse aspecto constitutivo se associa à capacidade dos objetos de design anônimo de incluir em sua configuração uma possibilidade de uso e a comunicação dessa possibilidade, conferindo aos elementos constitutivos dos objetos um valor sempre duplo: comunicativo além de funcional.

Se é impossivel estabelecer uma gramática que nos indique como produzir bons objetos de design, gostaria de tentar investigar um único objeto eficaz e comparar sua organização interna com as características já apontadas por nossos heróis anônimos. Gostaria, então, de destacar algumas características do objeto eficaz que atravessam transversalmente as tipologias consideradas e que podem encontrar-se, na minha opinião, tanto no design anônimo, cuja existência se deve apenas à sua eficácia, como em certos objetos de design autoral que se tornam de uso comum, a ponto de nos fazer esquecer seus autores (refiro-me ao interruptor de Castiglioni, objeto que era o seu orgulho). Seus valores parecem construir-se inteiramente em torno das propriedades comunicativas e funcionais do objeto, atualizadas na interação com o usuário.

Assim, podemos reformular a pergunta inicial: É possivel pensar que alguns objetos, assinados ou não, reproduzidos em poucas cópias, milhares ou milhões, tragam em seu interno a configuração que permite que eles se tornem eficazes como os objetos de uso comum a que se referia Eco (1982)? Trata-se de investigar se a afirmação na cotidianidade de um objeto pode ser explicada semioticamente como eficácia comunicativa, ou seja, como capacidade própria do objeto de tornar competente, sensivel e cognitivamente, o seu usuário. Trata-se, portanto, de considerar os objetos como implicados em programas de ação e de comunicação, de comunicação de competência entre instâncias de ação. ${ }^{3}$

\section{A comunicação e o uso no design anônimo}

A minha hipótese é que a razão dessa eficácia esteja na articulação interna do objeto, no modo pelo qual se constitui enquanto correlação entre uma configuração da expressão e uma configuração do conteúdo, e que esse conteúdo seja constituído de instruções semânticas para o uso, para a colocação em prática, abrindo mão daquelas formas de redundância decorativas, figurativas ou não, que estão na moda na Disneylândia não-figurativa, como Paolo Fabbri e Giovanni Careri carinhosamente chamaram o design atual. ${ }^{4}$

Poderíamos começar por uma definição negativa: procurando definir o que não é o design anônimo. Um exemplo poderia ser os objetos seriais que nascem por imitação e degradação dos objetos de design assinados. Esses objetos - ao perderem a autoralidade que caracteriza o design assinado - não possuem a eficácia comunicativa e prática que caracteriza o design anônimo, tornando-o um produto de qualidade, mesmo sendo fruto de uma inteligência prática difusa, não atribuída a uma categoria comercial - ou romântica - do autor ou do artista.

0 exemplo sobre o qual me deterei é constituido por dois copos, escolhidos para comparar justamente porque à primeira vista são idênticos, que poderiam ser decompostos de acordo com os procedimentos típicos da semiótica plástica de Floch (1995) para comparar os canivetes Opinel e Victorinox, que aqui retomaremos com ligeira modificação.

0 primeiro dos nossos objetos (Figura 1) é um objeto de design (produzido pela Revol) do qual não se conhece o autor ou criador, mas apenas o nome, que, entre outras coisas, é uma pura descrição do objeto (Crumple espresso cup). Trata-se de um copo amassado feito de porcelana, que imita um copo plástico usado (e destruído pelo uso). 0 segundo (Figura 2) é uma imitação deste objeto que encontrei em um mercado. A contradição entre o aspecto figurativo do objeto e o material do qual é fabricado - a porcelana - representa o elemento que o torna imediatamente reconhecível, pelo menos à primeira vista. 
Já bastante conhecido, trata-se de um copo de porcelana que imita um plástico submetido a uma forte pressão manual, que o deforma, amassando-o. 0 copo de porcelana indeformável imita porém subverte-a, porque torna fixa e imóvel a deformação súbita do plástico.

Isso é o que é projetado visualmente para parecer plástico, mas o material do qual ele é composto o torna de fato indeformável: desse modo é, ao mesmo tempo, deformado e indeformável. Mas no copo de design anônimo torna-se visivel um projeto comunicativo que supera o aspecto meramente figurativo: valoriza o efeito do amassado, transformando-o em uma instrução para o uso (Fabbri, 2005), e inscrevendo, dessa forma, no elemento que confere ao objeto uma visibilidade e um reconhecimento - além de uma valência irônica - um programa de ação e de comunicação. De que maneira?

Apenas tocando o objeto se pode entender a diferença entre os dois copos. Ambos são na verdade divididos em três partes, duas lisas e uma estriada, atravessadas por linhas horizontais que recobrem parcialmente o ponto de amassadura.

0 objeto de design anônimo do ponto de vista do uso não é absolutamente anônimo: apresenta no ponto da amassadura uma marcação da superfície que permite segurar o objeto sem que ele escorregue. Estas linhas estão ausentes no resto da superfície do objeto. Assim, não tem apenas um valor estético (enfatizar a amassadura) ou funcional (evitar que a mão escorregue), mas ligado a uma prática que representa as instruções de uso: assinalam também - pela diferença, já que que estão presentes apenas em uma parte específica da superfície do objeto - o ponto de pegada correto para segurar o objeto. Indicam portanto o que fazer - segurar apertando com a mão, como no caso de qualquer outro copo -, e também onde o fazer: não por acaso a amassadura do copo é estruturada para acomodar perfeitamente a parte dos dedos da mão que 0 circundam. A indicação para o - uso ou seja, a inscrição de um programa de ação comunicado por meio da configuração plástico-textural - é unida à função estética. Esta capacidade de sintese torna esse objeto interessante: o fato de que um único elemento plástico, a superfície entalhada, sirva para definir uma diferença significativa, com valor estético e funcional, mas sobretudo comunicativo; enquanto evidencia a existência da amassadura, essa diferença textural comunica um programa de uso: pegue-me aqui, diz o copo. E um único signo - a diferença no tratamento da superfície do objeto funciona como sinal indicial, comunicando um possível uso (se quiser, ideal) para seu usuário, além de assumir uma função (não deixar escorregar a mão). Funções estética, prática e comunicativa são expressas por um único signo então, um elemento diferencial que permite ao mesmo tempo criar uma dupla relação: 1) com o resto do objeto, destacando uma parte em relação às outras; 2) com o usuário, indicando como este ponto diferencial é um lugar de pegar, mostrando assim a forma de utilização do objeto. A capacidade de síntese do design anônimo, devidamente assinalada por Eco, surge dessa capacidade de associar uma série de significados a um único elemento do objeto, definido por uma qualidade diferencial específica. A comunicação e a colocação em prática, a possível ação do usuário, no design anônimo são comunicadas por meio da configuração diferencial do objeto. 0 conceito de affordance, proposto por Gibson, enquanto relação e ação possível entre sujeito e objeto, discutido por Eco (1997), poderia ser, pelo menos nesse caso específico, investigado também no nível da relação entre os componentes do objeto, como sugere a observação da cópia deste copo (Figura 2).

A cópia é à primeira vista idêntica, assim como algumas imperfeições (redução excessiva das bordas superiores, o que facilita o vazamento de líquido, relevo acentuado da amassadura no interior do copo, o que reduz a capacidade de armazenamento), e o uso de materiais de qualidade inferior apresenta uma diferença importante: as linhas horizontais na superfície são apenas visíveis, mas praticamente não são sentidas ao toque. Trata-se, conforme podemos supor, do elemento mais dispendioso em termos de tempo e equipamento, e, por conseguinte, mais custoso e complexo de se reproduzir. Eliminá-lo - mantendo apenas a aparência figurativa - produz a perda completa da função comunicativa e, assim, a capacidade de orientar a mão (ou seja, o objeto com o qual o copo entra em contato), apagando o programa de comunicação de ação inscrito no objeto e reconduzindo o signo a uma única função, puramente estética. Essa perda da capacidade de expressar a sintaxe de ação inscrevendo-a na configuração do objeto empobrece muito a cópia em comparação com o modelo de que é replica, tornando-a apenas uma pálida imitação. Não se trata mais de design, mas de uma banalização serial. É assim que o objeto de design e a cópia banal encontram a sua diferença em uma configuração sintática e semântica, e não mais apenas no problema da autoria. 


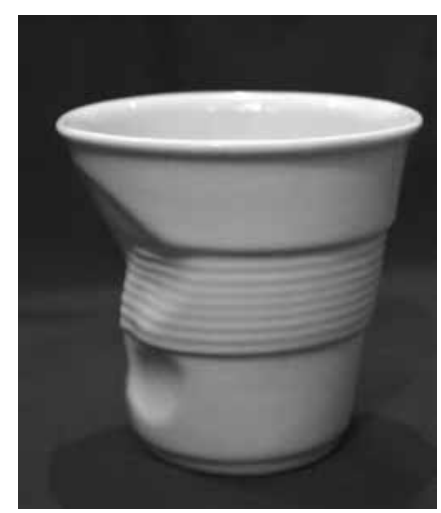

Figura 1

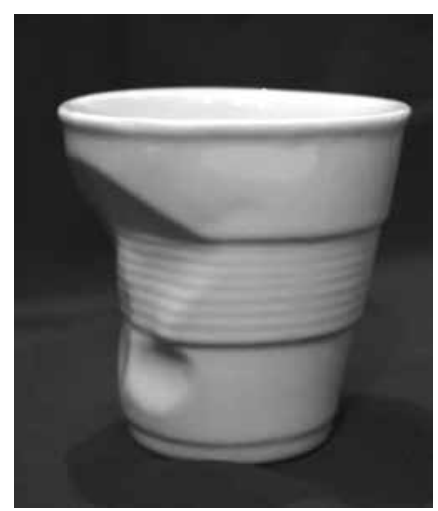

Figura 2

\section{Considerações finais}

Nossa tese é, portanto, que os objetos de design anônimo são caracterizados por um projeto que envolve programas de ação e de comunicação inscritos em suas configurações. Por meio do componente estético, transmitem instruções para uma utilização otimizada. Inscrevem, então, na configuração plástica a função prática do objeto e, simultaneamente, a comunicação dessa função, o uso do objeto e a comunicação de seus programas de uso. E essa instrução para o uso joga com o componente estético do objeto não se limitando a ele, mas unindo o valor estético, funcional e comunicativo.

Mesmo em uma sociedade industrial como a nossa, que há muito tempo reduziu o espaço simbólico dado nas sociedades tradicionais a determinados tipos de objetos (como a fechadura Dogon descrita por Greimas, 1987), parece ser, de qualquer forma, um excedente de sentido - unido a uma subtração de elementos e de decoração - que faz a diferença.

\section{NOTAS}

${ }^{[1]}$ Tradução: Simone Bueno.

[2] De acordo com Eco (1982, p. 132): "Há influências e adaptações que unem as propostas do design assinado aos êxitos do design anônimo (assim como o design inconsciente muitas vezes inspirou o design assinado)".

${ }^{[3]}$ Conforme Fabbri (1999) e Mattozzi (2006).

${ }^{[4]}$ De acordo com Careri e Fabbri (1994).

\section{REFERÊNCIAS}

BASSI, A. Design anonimo in Italia. Milano: Electa, 2007.

CARERI, G.; FABBRI, P. Cose d'Alessi: la felicità e la cura. In: AA.W. Le fabbriche del design italiano: Alessi: une dynastie d'objets. Roma: Carte Segrete, 1994. ECO, Umberto. Anche questi fenomeni debbono far parte di un panorama del design italiano:altrimenti non si capisce né cosa sia l'Italia né cosa sia il design. In:

ECO, Umberto. Anche questi fenomeni debbono far parte di un panorama del design italiano: altrimenti non si capisce né cosa sia l'Italia né cosa sia il design. In: SARTOGO, Piero (Org.). Italian re-evolution, design in italian society in the eighties. Milano: Nava, 1982.

. Kant e l'ornitorinco. Milano: Bompiani, 1997.

FABBRI, P. Oggetti come segni: programmi d'azione e di comunicazione. In: AA.W. VALERIO, F. di (Org.). Contesto e identità:gli oggetti fuori e dentro i musei. Bologna: Clueb, 1999.

Istruzioni e pratiche istruite: trascrizione della relazione tenuta al convegno"Le pratiche semiotiche: la produzione e l'uso" da E|C. Rivista dell'Associazione Italiana di Studi Semiotici on-line, San Marino, n. 10-12, giug. 2005.

FLOCH, J. M. Identités visuelles. Paris: Presses Universitaires de France, 1995. GREIMAS, A.J. Dell'imperfezione. Palermo: Sellerio, 1987. MATTOZZI, A. II senso degli oggetti tecnici. Roma: Meltemi, 2006.

GREIMAS, A.J. Dell'imperfezione. Palermo: Sellerio, 1987.

MATTOZZI, A. II senso degli oggetti tecnici. Roma: Meltemi, 2006.

PARIS, T. Mass design o il potere dell'oggetto anonimo. DIID - Disegno Industriale, n. 15, giugl.-ago., p. 4-5, 2005. 